\title{
Psychological and Biomechanical Aspects of Patient Adaptation to Diabetic Neuropathy and Foot Ulceration
}

\author{
Loretta Vileikyte ${ }^{1}$, Ryan T. Crews ${ }^{2}$, Neil D. Reeves ${ }^{3}$ \\ ${ }^{1}$ Dept of Medicine, University of Manchester, Manchester, M13 9WL, UK \\ ${ }^{2}$ William M. Scholl College of Podiatric Medicine, Rosalind Franklin University of \\ Medicine and Science, North Chicago, IL 60064, USA \\ ${ }^{3}$ School of Healthcare Science, Faculty of Science \& Engineering, Manchester \\ Metropolitan University, Manchester M1 5GD, UK
}

\begin{abstract}
The purpose of this review is to elucidate how psychological and biomechanical factors interrelate in shaping patients' experience with diabetic symmetric polyneuropathy (DSPN) and its sequela- diabetic foot ulceration (DFU). Recent findings emphasize the importance not only of neuropathic pain but also of other DSPN symptoms, such as unsteadiness. We highlight the negative spiral between unsteadiness, falls and psychological distress. Moreover, unsteadiness is a key determinant of non-adherence to offloading resulting in the delayed DFU healing. While depression is an established predictor of incident DFU, findings linking depression and DFU healing remain inconclusive. Examination of physical activity in DFU development and healing represents the most recent application of research to this field. Summary: Research evidence indicates that DSPN markedly impairs physical and emotional functioning and suggests that there is an unmet need for the development of multifaceted interventions that address both psychological distress and biomechanical challenges experienced by patients with this debilitating complication of diabetes.
\end{abstract}

Key words: diabetic symmetric polyneuropathy; pain; unsteadiness, foot ulcers, depression, illness cognition and emotion; offloading adherence; physical activity

\section{Correspondence:}

Loretta Vileikyte, MD, PhD

Ivileikyte@med.miami.edu 


\section{Introduction}

The diabetic neuropathies are a collection of nerve disorders caused by diabetes that affect different parts of the nervous system and present with diverse clinical manifestations (1*0) Distal symmetric polyneuropathy (DSPN) is one of the commonest varieties and is the focus of the current review. There are two major clinical consequences of DSPN: neuropathic pain and peripheral insensitivity. The latter predisposes patients to foot ulceration and amputation through unperceived trauma and through structural changes such as foot deformities and high pressure areas under the feet that may subsequently ulcerate. We examine two relatively distinct areas of patient adaptation to DSPN: 1) the impact of DSPN on psychosocial outcomes, including depression, anxiety and quality of life (QoL), and 2) the role of psychological and biomechanical factors in shaping preventive foot self-care and diabetic foot ulcer (DFU) management. The importance of complications including DSPN was recently acknowledged by a position statement regarding psychosocial care for people with diabetes by the American Diabetes Association (2••). The recommendation was made to "routinely monitor people with diabetes for depression, anxiety and diabetes distress particularly at the onset of diabetes complications". Among the various clinical presentations of DSPN, severe unremitting pain and foot ulceration are by far the most studied by the behavioral scientists. Our review, while reflecting this common tendency, highlights the importance of other clinical presentations of DSPN. Unsteadiness, for example, is one of the strongest predictors of depression in patients with established DSPN $(3 \cdot, 4)$ and is an important determinant of non-adherence to offloading that plays a key role in diabetic foot ulcer (DFU) healing (5•). Moreover, we emphasize the implications of DSPN-specific cognitions and emotions in shaping preventive foot selfcare and examine the role of depression in DFU development and healing. We complete our review by discussing perhaps the most recent application of research to this field, that is, the interplay between the psychological and biomechanical effects of DSPN when considering patient engagement in physical activity.

\section{The Impact of Diabetic Symmetric Polyneuropathy on Physical and Mental Functioning}

Although DSPN is a multifaceted complication of diabetes, studies examining the impact of DSPN on individuals' physical and psychosocial functioning have traditionally focused on neuropathic pain. One of the earliest, yet probably most comprehensive assessments to-date of neuropathic pain burden, was conducted by Gore at al. $(6,7 \cdot)$. The burden of pain was reported to be extensive, resulting in a persistent discomfort despite polypharmacy and leading to poor satisfaction with treatment. The effectiveness of treatment was often reduced due to dose-limiting side effects, leaving DSPN patients in continuing pain. Furthermore, greater pain levels corresponded with higher symptom levels of anxiety and depression, more sleep problems, and lower ratings of functioning. High levels of emotional distress in these patients were recently corroborated by Selvarajah et al (8) in a study that highlighted the differing independent contributors to anxiety and depressive symptoms based on an individual's circumstances and experience.

Making a Case for DSPN-specific Assessments of Quality of Life 
Cross-sectional and longitudinal studies in DSPN that employed generic measures of health status and quality of life (QoL), such as the most commonly used, the Short Form (SF)-36, revealed a common pattern, that is, that DSPN affects health predominantly in the domain of physical functioning: the impact of DSPN on mental functioning was nonsignificant in most of these reports. This pattern holds regardless of whether DSPN is measured by clinical tests of neurologic dysfunction (9) or by patient somatic experience with DSPN (10). The authors of these reports therefore concluded that DSPN is "strictly related to the physical aspects of the patients' quality of life, and not the mental aspects." However, the conclusion that DSPN and its clinical manifestations do not impact mental function is not necessarily valid, in view of more recent studies linking DSPN to notably elevated levels of anxiety and depression $(3 \cdot, 4)$. The alternative explanation could be that the generic measures of functioning do not capture adequately neither generalized nor DSPN-related emotional disturbance. The results of a comprehensive review that assessed the impact of neuropathic pain on QoL (11) support this proposition. It provides evidence that the condition-specific QoL measures are more sensitive to the effects of neuropathic pain than the generic instruments especially in the domain of mental functioning.

In an attempt to overcome the limitations of the generic instruments, several DSPN-specific measures have been developed. The health-related QoL measure by Vickrey et al. (12) was developed for the assessment of QoL in patients with various peripheral neuropathies including DSPN. The 47-item Norfolk QoL-DSPN, in addition to the generic health status and general information items, includes a comprehensive measure of DSPN symptoms and the specific ways these symptoms impact on ADL (13). The 35-item NeuroQoL is a hierarchically organized scale that assesses the patient subjective reports of functioning and QoL in six specific domains (14) including DSPN-specific somatic experiences (pain, unsteadiness and symptoms of reduced feeling in the feet), social and personal dysfunction and emotional states, and the two final items requesting that the patients appraise the impact of DSPN on their QoL and provide an overall QoL evaluation. The psychometric analyses that compared the performance of the NeuroQoL to the SF-12 demonstrated that the NeuroQoL was more strongly associated with DSPN severity, more fully mediated the relationship of DSPN with QoL, and significantly increased explained variance in QoL judgement over the SF-12. Taken together, it appears that DSPN-specific scales capture more adequately than generic measures the impact of DSPN on an individual's functioning, especially in the emotional domain.

The effects of DSPN on patients' quality of life (QoL) are emerging as an important component of patient care and may play a significant part in adherence and response to therapies. A study by Otto et al. (15) is one of the few reports that examined the impact of patient emotional and physical functioning, as measured by the SF-36, on their response to treatment for painful DSPN. The researchers demonstrated that the SF-36 scores predicted patients' response to treatment after controlling for demographic variables, pain duration and intensity. The authors therefore suggested that psychosocial factors might provide a useful guide in selecting the patient populations most responsive to treatment for painful DSPN.

\section{Pathways Linking DSPN and its Symptoms to Depression and Anxiety}

Earlier reports examining the link between DSPN and depressive symptoms have produced inconsistent results, although a meta-analysis suggested that there is a 
significant association between depression and diabetes complications, including DSPN (16). Vileikyte et al (3•) examined cross-sectionally the relationship between DSPN and depression and explored the potential physical and psychosocial mediators of this association. This study departed from earlier reports in several important ways: 1) the participant selection was based on well- established tests of neurologic dysfunction rather than the presence of DSPN symptoms or foot ulceration alone, and 2) it assessed the independent contributions of a variety of DSPN somatic experiences to depression. The results of this cross-sectional report demonstrated that DSPN severity is significantly associated with depression, as measured with the Hospital Anxiety and Depression Scale (HADS). Self-reported neuropathic pain, unsteadiness, and reduced feeling in the feet were each independently associated with depression and together accounted for the relationship between the clinical measures of DSPN severity and depression. Furthermore, the association between DSPN symptoms and depression was partially mediated by two sets of psychosocial factors: 1) restrictions in ADL and diminished self-worth, and 2) illness cognition, or the perceptions of neuropathic pain unpredictability and the lack of treatment control. The longitudinal findings were largely consistent with the cross-sectional observations and demonstrated that more severe DSPN at baseline is associated with worsening depressive symptoms over 18 months of follow-up (4). While neuropathic pain contributed to depression, unsteadiness and its psychosocial consequences dominated this relationship over time. Curiously, neuropathic pain displayed a persistent relationship with anxiety. The enduring relationship between painful neuropathy and anxiety is consistent with the general literature linking chronic pain and anxiety; this pattern mirrors but exceeds the pattern for research examining depression and chronic pain (17). These results suggest that clinicians should monitor the dynamics of affect and select treatment based on the predominant type of emotion, especially as commonly used medications for painful DSPN are potent mood modulators with distinct class effects on anxiety and depression $(18,19)$.

\section{The Importance of DSPN-related Unsteadiness in Generating Psychological Distress}

The emergence of unsteadiness as the symptom that is most strongly associated with depression merits attention. We demonstrated that unsteadiness is common, with nearly a quarter of DSPN patients reporting balance problems as present either most or all the time (3•). Unfortunately, balance deficits may be overlooked by clinicians, as patients often do not report balance concerns during medical consultations owing to the perception that these are an indicator of diminishing self-resources-a sign of premature aging rather than illness-related disability (14). Importantly, however, these patients have a $\sim 20$-fold greater risk of falling compared to aged-matched controls (20). The physical outcomes of falling include serious injury (21) and even an increased risk of mortality $(22,23)$.

The consequences of falling, however, are not only physical but also psychological, such as poor self-efficacy with walking and fear of falling (24). This highlights the negative spiral between DSPN, unsteadiness, falls and psychological distress. The necessity of explicitly looking at biomechanical components is supported by the results 
of a cross-sectional study (25) that found fear of falling was not significantly correlated with a clinical measure of DSPN, but fear of falling was significantly associated with a number of gait parameters such as slower stride velocity and shorter stride lengths. While the study by Kelly et al. failed to show a direct linear association between fear of falling and DSPN, the gait parameters found to be associated with fear of falling have been shown in a meta-analysis to be associated with the presence of DSPN (26).

A recent study (27•) examined how yet another subjective measure - self-perceived unsteadiness - influences gait characteristics and balance in DSPN patients. Selfperceived unsteadiness was assessed with the NeuroQoL and compared against laboratory measurements of walking (27•). The study demonstrated that perceptions of unsteadiness reported prior to laboratory tests correlated with objective measures of balance impairment during walking. Moreover, DSPN patients were not only aware of themselves as being unsteady but actually attempted to self-regulate their unsteadiness by altering specific gait parameters. As a result of feeling unsteady, patients with diabetic peripheral neuropathy adjusted their gait by walking more slowly and taking shorter steps (Fig. 1). While these 'self-initiated' strategies are likely to be beneficial to a certain extent, they seem to be insufficient for effective balance control since impairments in body center of mass movement and dynamic sway are still evident in DSPN patients when compared to patients with diabetes without DSPN and to matched controls without diabetes $(27 \cdot, 28 \cdot)$. These findings necessitate the search for more effective biomechanical approaches to balance control in patients with DSPNunsteadiness.

The results of several exercise-related interventions appear promising for improving DSPN-related balance impairments. A systematic review and meta-analysis of randomized controlled trials (RCTs) indicate that foot and ankle exercise can improve certain fall risk-related motor outcomes and reduce falls in older adults (29). The results of a RCT using sensor-based exercise with real-time visual feedback of performance demonstrated that people with DSPN can significantly improve their standing postural balance (30). In another exercise intervention study, DSPN patients performed resistance exercise training for 16 weeks and showed improvements in the speed of strength generation in the major knee and ankle extensor muscles while walking on stairs (31).

Although no psychosocial interventional studies to date have been performed in people with DSPN-related unsteadiness, some positive effects on reducing falls have been achieved in high-risk older adults. One multifactorial intervention that did significantly reduce the risk of falling in at-risk elderly patients utilized a cognitive-behavioral skills learning approach (32). The intervention program aimed to improve self-efficacy for preventing falls, encourage behavior change, and provide education about risk management. Over 14 months of follow-up, intervention group participants experienced a clinically meaningful $31 \%$ reduction in falls. Furthermore, intervention recipients were more confident in their ability to avoid a fall during a variety of functional daily living tasks and used more protective behavioral practices than control participants. Similar methodologies adapted for patients with DSPN could be effective and deserve empirical evaluation. 
Considering the above discussion, clinicians should therefore address unsteadiness as a key symptom when assessing patients with DSPN. The patient's perception of their unsteadiness appears to be an adequate indicator of the actual balance impairment (27•). Pending a definitive intervention study, clinicians should consider a multifaceted approach to the management of patients with DSPN including a biomechanical component (physical adaptation to unsteadiness to improve safety) and a psychosocial component (strategies aimed at increasing participation in daily activities and enhanced perceptions of competence in important social roles). The importance of unsteadiness as a symptom of DSPN should receive attention in the education of both healthcare providers and patients.

\section{Depression, Preventive Foot Self-Care and Diabetic Foot Ulceration: is There a Link?}

Somewhat unexpectedly, neither prior nor active DFUs were independently associated with depression in the reports that examined the association between DSPN and depression $(3 \cdot, 4)$ This observation was corroborated by a large epidemiologic crosssectional investigation from Norway (33). Among people with diabetes, a history of foot ulcer while having a significant negative impact on perceived health did not independently contributed to HADS depression scores. Nonetheless, even though DFUs are not independently associated with depression, they serve as a marker for an increased risk for elevated depressive symptoms. Therefore, DFU patients should be carefully monitored to determine whether they are depressed, especially in the light of findings linking depression to an increased mortality in this patient population $(34,35)$.

While research has failed to establish a causal link between foot ulceration and depression, mounting evidence indicates that depression plays an important role in DFU development. An epidemiologic study has shown that major depression assessed by Patient Health Questionnaire-9 had a 2-fold increase in the risk of incident diabetic foot ulcers. There was no statistically significant association between minor depression and incident diabetic foot ulcers (36*). These observations were further solidified by an epidemiologic investigation demonstrating a link between symptoms of depression and an increased DFU risk in a dose response manner during an 11-year follow-up (37).

Similarly, another prospective study of well-defined DSPN population showed that both foot self-care and depression, while having no impact on the development of recurrent DFU, play a substantial role in incident foot ulceration in high-risk patients with no prior DFU (38•). In patients with no prior DFU depression symptoms were significantly associated with increased risk of developing first foot ulcers, while foot self-care was associated with lower risk. The fact that depression, like foot self-care, was associated with DFU risk only in those without a prior DFU suggests that the effects of these psychological and behavioral factors may not be robust enough to come into play in the context of very high levels of risk. Thus, addressing the psychological and behavioral factors in those patients with previous DFU may be "too little, too late."

Counterintuitively, depression, while predictive of DFU incidence, was not associated 
with poor adherence to foot self-care in this report. This challenges the assumption that nonadherence to foot self-care is the mechanism linking depression to DFU incidence. The finding is consistent with the meta-analytic review of the studies that examined the relationship between depression and a variety of diabetes self-care behaviors (39). The effect of depression on self-care varied across different types of self-care behaviors in this meta-analysis, with the strongest effect size found for missed medical appointments and the smallest effect size found for foot self-care, which was nonsignificant. Whether depression represents an indicator of biological risk that was not captured by the risk factors measured in these studies or whether it truly is a causal agent, acting via mechanisms other than foot self-care, in the development of foot ulcers, is an important question that deserves further investigation.

\section{The Role of Illness Cognition and Emotion in Shaping Preventive Foot Self-Care}

Whereas the relationship between depression and preventive foot self-care requires further clarification, a growing body of evidence indicates that illness-specific cognitions and emotional responses are more important predictors of self-care behaviors than the measures of generalized distress. Several studies have successfully adapted the Common Sense Model (CSM) of illness behavior (40) to explain preventive foot selfcare in patients at high DFU risk $(41 \cdot, 42)$. The first such study developed and validated the Patient Interpretation of Neuropathy (PIN) questionnaire, an instrument for assessing cognitive and emotional factors associated with foot self-care. Using the PIN instrument, this study demonstrated that patient misconceptions about DFU risk are associated with potentially foot- damaging behaviors. In contrast, accurate interpretation of medical information about the nature of DFU risk and understanding of the causal pathways linking DSPN to DFU is associated with more preventive foot self-care. Moreover, the study demonstrated that anger at practitioners stemming from a perceived lack of compassion hinders foot self-care, while worry about an amputation promotes foot self-care actions $(41 \cdot)$. Subsequently, a cross-sectional study of DSPN patients employed the PIN and hierarchical cluster analyses to identify distinct illness schemata related to neuropathy. The cluster of patients with high misperceptions of DSPN undertook more potentially damaging foot-care behaviors than those with generally realistic beliefs about the nature of neuropathy as a DFU risk factor (42).

There is evidence that beliefs about treatment are at least as important as beliefs about illness in predicting health-related behaviors (43). An investigation of patients that had been provided custom-made footwear for preventing secondary DFU found that the perceived benefit of the footwear was the only significant predictor of self-reported adherence (44). The same group had published data regarding objectively measured adherence to custom-made footwear for DFU prevention and found that in addition to lower BMI and more severe foot deformity, the subjective perception of more appealing footwear was significantly associated with better adherence to prescribed footwear (45).

\section{Psychological and Biomechanical Implications of DSPN regarding Physical Activity}

There is an obvious connection between the psychological and biomechanical effects of 
DSPN when considering engagement in physical activity by DSPN sufferers (46•). Both DSPN patients and their clinicians may be hesitant to increase physical activity because of their awareness of DFU risks. However, physical activity is not contraindicated in individuals with DSPN in spite of their heightened risk of DFU. On a contrary, exercise is actually recommended for this population $(47,48)$. Supervised weight-bearing exercise intervention studies in DSPN patients have collectively found significant improvements in physical activity without increasing the risk of ulceration (46•). (Table 1)

Depression is among the well-established barriers to physical activity. A 5-year longitudinal study of patients with diabetes found that those who experienced persistent or worsening depressive symptoms were less likely to engage in regular exercise (49). Although improvements in strength and balance through physical activity may lead to a reduction in risk of falls, another obstacle to consider regarding physical activity engagement is the potential for falls to occur while participating in physical activity (46, 50 ). The relationship between neuropathic pain and depression may further magnify challenges to initiate exercise in this population. Although pain may be a barrier to exercise in patients with diabetes, initial evidence suggests that exercise may actually alleviate pain $(51,52)$. While promising, small sample sizes and absence of a control group or long-term follow-up in these reports limit our ability to recommend exercise for the alleviation of DSPN pain.

\section{The Impact of Depression on DFU Healing}

Exploring the role of depression in DFU healing represents the most recent application of psychosocial research to this field, emerging from studies that examined the relationship between psychological stress and the healing of acute wounds, both in rodent models and human volunteers (53••).

The first such study in DFU patients examined the role of geriatric depression in foot ulcer healing over a six-month follow-up (54•). Healing was associated with a smaller DFU area at baseline, lower glycated hemoglobin and higher ankle-brachial index. Both smoking status and DFU severity had a significant negative impact on healing. Importantly, patients who healed had significantly lower scores on the geriatric depression scale. A subsequent investigation (55) considered the role of depression and coping styles in the healing of DFUs over a 24-week period. Additionally, explored were salivary cortisol and matrix metalloproteinases (MMPs) as potential mechanisms linking depression to DFU healing. After controlling for clinical and demographic determinants of healing, ulcer healing at 24 weeks (primary outcome) was predicted by confrontation coping, but not by depression or anxiety. However, change in ulcer size over the observation period (secondary outcome) was associated with depression only. Furthermore, healed ulcers by 24 weeks were associated with lower evening cortisol, lower precursor MMP2 and a greater cortisol awakening response. While an interesting undertaking, this report has several methodological issues (56). The presented data provided no mechanistic evidence, but merely demonstrated that indicators of cortisol and MMPs are associated with ulcer healing. It is not reported whether these potential 
mediators were associated with the predictors in question (i.e. depression and confrontational coping), or whether controlling for the purported mechanisms attenuated the relationship between the predictors and outcome. Restricting their analyses to those with complete data on these variables would also have addressed the possibility that the reported differences in the associations between depression, confrontational coping and healing outcomes may have been due to chance variations in the relationships between these variables across quite different samples.

A recently conducted small scale study (57) examined the effects of physiological stress on DFU healing speed defined as percentage change in wound size between the two consecutive visits. While there was a moderate but significant correlation between depression scores and physiological stress/vagal tone, an association between depression and DFU healing was not observed. In contrast, lower heart rate variability (a proposed indicator of physiological stress response) showed a significant correlation with slower DFU healing. The authors therefore concluded that subjective stress assessments may not capture adequately the level of physiological stress, and that it is the physiological and not psychological stress that delays the healing of DFUs. However, the sudy population does not appear to be sufficiently clinically defined. For instance, the subjects in this report might have had cardiac autonomic neuropathy in which case the heart rate variablity may not have been the best measure of physiological stress response. As a result, definitive conclusions regarding the role of depression in DFU healing cannot not be drawn from these reports.

\section{The Role and Determinants of Adherence to Offloading in Diabetic Foot Ulcer Healing}

Although clinical opinion suggests the importance of adherence to off-loading in DFU healing, the relationship between objectively measured offloading adherence (OA) and DFU healing has now been confirmed (5•). Off-loading adherence was associated with the rate of DFU healing that occurred during the 6-week follow-up, while DSPNunsteadiness emerged as a powerful predictor of nonadherence. Depression was not significantly associated with $\mathrm{OA}$ in this report. These observations require one to take DSPN-unsteadiness into consideration when selecting an off-loading device, as offloading-induced postural instability may further compromise pre-existent unsteadiness thereby contributing to nonadherence.

While a few publications have focused upon the effect of offloading devices upon the users' stability (58-60), to date there has been a lack of studies investigating ways of improving offloading adherence (61). Most studies evaluating offloading devices focus on the devices' functional capacity to offload wounds. However, they rarely seek to improve the patient experience. One study that focused on design considerations that could improve the patient experience found that a reduction in cast walker height (and subsequently weight) did not substantially reduce offloading functionality (62). However, the reduction in walker height did yield some trends of improved gait parameters. Taking such a patient centered approach to prescribing and designing 
offloading devices may result in improved patient adherence.

\section{Physical Activity and DFU Healing}

Management of physical activity in patients with active DFUs is poorly understood. There is evidence that physical exercise accelerates wound healing in rodents and humans (63-66) although the mechanisms are not clear. It has been postulated that exercise mitigates the negative effects of psychological stress on wound healing (67), reduces inflammation (68) and increases peripheral blood flow (69).

Najafi et al (70•) investigated patterns of physical activity and their relationship to wound healing in patients with DFUs protected with either a removable cast walker (RCW) or irremovable instant total contact cast. Irrespective of offloading modality, there was an inverse association between rate of weekly wound healing and number of steps taken per day. However, as noted by the authors, the study did not control for offloading adherence in the RCW group. It remains therefore unclear whether the relationship between physical activity and healing varied as a function of $O A$. The results of a secondary analysis of an international UK/US study of subjects with plantar DFUs suggest that offloading-adherent weight-bearing physical activity has no independent effect on healing (71). At the bivariate level, daily step count and adherence to a removable offloading device were each significantly associated with smaller DFU at 6 wks. However, in multivariate analyses controlling for OA, the association of daily step count with DFU healing was no longer significant. Interestingly, among the potential demographic, disease and psychological determinants of physical activity, only depression was significantly independently associated with lower step count.

Depression should therefore be targeted as part of comprehensive DFU management, especially in light of findings linking depression to neuropathic unsteadiness - a key predictor of nonadherence to offloading and, in turn, impaired foot ulcer healing. These observations are a perfect example of how psychological (depression) and biomechanical (unsteadiness-offloading) factors interrelate in shaping patient selfmanagement of DFU.

\section{Conclusions}

Our review demonstrates that DSPN is a source of physical dysfunction, psychological disturbance, and diminished QoL. DSPN-specific scales capture more adequately than generic measures the impact of DSPN on an individual's functioning, especially in the emotional domain. Whereas neuropathic pain contributes to depression, unsteadiness is the symptom with the strongest, cumulative effect on depression. Moreover, unsteadiness is the key determinant of nonadherence to offloading in active DFU patients. Clinicians should therefore address unsteadiness when assessing patients with DSPN, especially as the patients' perception of their unsteadiness appears to be an adequate indicator of the actual balance impairment. Although DSPN-specific cognitions and emotions influence preventive foot self-care, it is depression that is associated with an increased risk for DFU, the link that does not appear to be accounted for by poor foot self-care. Thus, the pathways linking depression to an increased DFU risk are yet to be established. While a growing body of evidence 
indicates that depression is an important risk factor for incident DFU, the findings linking depression to DFU healing remain inconclusive. Finally, our understanding of the management of physical activity in DSPN patients is still in its infancy, although a growing body of evidence indicates that supervised weight-bearing exercise interventions are beneficial and do not increase the DFU risk. More research is needed to guide the management of physical activity in patients with active DFUs. Taken together, these findings necessitate the development of multifaceted interventions that address both psychosocial distress and biomechanical challenges experienced by DSPN sufferers.

\section{Acknowledgement}

We thank the NIH (NIDDK R01-DK-071066) for their generous support of some of the studies reported in this review. 


\section{References}

Papers of particular interest, published recently, have been highlighted as:

- Of importance

• Of major importance

1.• Pop-Busui R, Boulton AJ, Feldman EL, Bril V, Freeman R, Malik RA, et al. Diabetic Neuropathy: A Position Statement by the American Diabetes Association. Diabetes Care. 2017:40(1):136-54. A comprehensive review of diagnostic tools and treatment options for diabetic neuropathies.

2.• Young-Hyman D, de Groot M, Hill-Briggs F, Gonzalez JS, Hood K, Peyrot M. Psychosocial Care for People With Diabetes: A Position Statement of the American Diabetes Association. Diabetes Care. 2016:39(12):2126-40. Evidence-based guidelines for psychosocial assessment and care of patients with diabetes and their families.

3. Vileikyte L, Leventhal H, Gonzalez JS, Peyrot M, Rubin RR, Ulbrecht JS, et al. Diabetic peripheral neuropathy and depressive symptoms: the association revisited. Diabetes care. 2005:28(10):2378-83. An important paper defines pathways linking distal symmetric polyneuropathy to depressive symptoms.

4. Vileikyte L, Peyrot M, Gonzalez JS, Rubin RR, Garrow AP, Stickings D, et al. Predictors of depressive symptoms in persons with diabetic peripheral neuropathy: a longitudinal study. Diabetologia. 2009:52(7):1265-73.

5. $\quad$ Crews RT, Shen BJ, Campbell L, Lamont PJ, Boulton AJ, Peyrot M, et al. Role and Determinants of Adherence to Off-loading in Diabetic Foot Ulcer Healing: A Prospective Investigation. Diabetes Care. 2016:39(8):1371-7.This study objectively demonstrates the association between off-loading adherence and diabetic foot ucler healing and identifies self-reported unsteadiness as a significant predictor of adherence to offloading.

6. Gore M, Brandenburg NA, Hoffman DL, Tai KS, Stacey B. Burden of illness in painful diabetic peripheral neuropathy: the patients' perspectives. J Pain. 2006:7(12):892-900.

7•. Gore M, Brandenburg NA, Dukes E, Hoffman DL, Tai KS, Stacey B. Pain severity in diabetic peripheral neuropathy is associated with patient functioning, symptom levels of anxiety and depression, and sleep. J Pain Symptom Manage. 2005:30(4):374-85. A thorough overview of neuropathic pain burden.

8. Selvarajah D, Cash T, Sankar A, Thomas L, Davies J, Cachia E, et al. The contributors of emotional distress in painful diabetic neuropathy. Diab Vasc Dis Res. 2014:11(4):218-25.

9. Padua L, Aprile I, Saponara C, Padua R, Ghirlanda G, Pauri F, et al. Multiperspective assessment of peripheral nerve involvement in diabetic patients. Eur Neurol. 2001:45(4):214-21.

10. Ahroni JH, Boyko EJ. Responsiveness of the SF-36 among veterans with diabetes mellitus. J Diabetes Complications. 2000:14(1):31-9. 
11. Jensen MP, Chodroff MJ, Dworkin RH. The impact of neuropathic pain on health-related quality of life: review and implications. Neurology. 2007:68(15):1178-82.

12. Vickrey BG, Hays RD, Beckstrand M. Development of a health-related quality of life measure for peripheral neuropathy. Neurorehabil Neural Repair. 2000:14(2):93-104.

13. Vinik EJ, Hayes RP, Oglesby A, Bastyr E, Barlow P, Ford-Molvik SL, et al. The development and validation of the Norfolk QOL-DN, a new measure of patients' perception of the effects of diabetes and diabetic neuropathy. Diabetes Technol Ther. 2005:7(3):497-508.

14. Vileikyte L, Peyrot M, Bundy C, Rubin RR, Leventhal H, Mora P, et al. The development and validation of a neuropathy- and foot ulcer-specific quality of life instrument. Diabetes Care. 2003:26(9):2549-55.

15. Otto M, Bach FW, Jensen TS, Sindrup SH. Health-related quality of life and its predictive role for analgesic effect in patients with painful polyneuropathy. Eur J Pain. 2007:11(5):572-8.

16. de Groot M, Anderson R, Freedland KE, Clouse RE, Lustman PJ. Association of depression and diabetes complications: a meta-analysis. Psychosom Med. 2001:63(4):619-30.

17. Asmundson GJ, Katz J. Understanding the co-occurrence of anxiety disorders and chronic pain: state-of-the-art. Depress Anxiety. 2009:26(10):888-901.

18. Tesfaye S, Vileikyte L, Rayman G, Sindrup SH, Perkins BA, Baconja M, et al. Painful diabetic peripheral neuropathy: consensus recommendations on diagnosis, assessment and management. Diabetes Metab Res Rev. 2011:27(7):629-38.

19. Marchettini P, Wilhelm S, Petto H, Tesfaye S, Tolle T, Bouhassira D, et al. Are there different predictors of analgesic response between antidepressants and anticonvulsants in painful diabetic neuropathy? Eur J Pain. 2016:20(3):472-82.

20. Schwartz AV, Vittinghoff E, Sellmeyer DE, Feingold KR, de Rekeneire N, Strotmeyer ES, et al. Diabetes-related complications, glycemic control, and falls in older adults. Diabetes Care. 2008:31(3):391-6.

21. DeMott TK, Richardson JK, Thies SB, Ashton-Miller JA. Falls and gait characteristics among older persons with peripheral neuropathy. Am J Phys Med Rehabil. 2007:86(2):125-32.

22. Dunn JE, Rudberg MA, Furner SE, Cassel CK. Mortality, disability, and falls in older persons: the role of underlying disease and disability. Am J Public Health. 1992:82(3):395-400.

23. Tan MP, Kamaruzzaman SB, Zakaria MI, Chin AV, Poi PJ. Ten-year mortality in older patients attending the emergency department after a fall. Geriatr Gerontol Int. 2016:16(1):111-7.

24. McKee KJ, Orbell S, Austin CA, Bettridge R, Liddle BJ, Morgan K, et al. Fear of falling, falls efficacy, and health outcomes in older people following hip fracture. Disabil Rehabil. 2002:24(6):327-33.

25. Kelly C, Fleischer A, Yalla S, Grewal GS, Albright R, Berns D, et al. Fear of falling is prevalent in older adults with diabetes mellitus but is unrelated to level of neuropathy. J Am Podiatr Med Assoc. 2013:103(6):480-8.

26. Hazari A, Maiya AG, Shivashankara KN, Agouris I, Monteiro A, Jadhav R, et al. Kinetics and kinematics of diabetic foot in type 2 diabetes mellitus with and without peripheral neuropathy: a systematic review and meta-analysis. Springerplus. 2016:5(1):1819. 
27. Reeves ND, Brown SJ, Petrovic M, Boulton AJM, Vileikyte L. How Does Self-Perceived Unsteadiness Influence Balance and Gait in People With Diabetes? Preliminary Observations. Diabetes Care. 2017:40(5):e51-e2. The study demonstrated the association between subjective (self-perceived unsteadiness) and objective (laboratory) measures of balance in people with diabetes and distal symmetrical polyneuropathy.

28.• Brown SJ, Handsaker JC, Bowling FL, Boulton AJ, Reeves ND. Diabetic peripheral neuropathy compromises balance during daily activities. Diabetes Care.

2015:38(6):1116-22. The study objectively demonstrated impaired balance in people with diabetic neuropathy compared to controls during daily tasks such as walking on stairs.

29. Schwenk M, Jordan ED, Honarvararaghi B, Mohler J, Armstrong DG, Najafi B.

Effectiveness of foot and ankle exercise programs on reducing the risk of falling in older adults: a systematic review and meta-analysis of randomized controlled trials. J Am Podiatr Med Assoc. 2013:103(6):534-47.

30. Grewal GS, Schwenk M, Lee-Eng J, Parvaneh S, Bharara M, Menzies RA, et al. SensorBased Interactive Balance Training with Visual Joint Movement Feedback for Improving Postural Stability in Diabetics with Peripheral Neuropathy: A Randomized Controlled Trial. Gerontology. 2015:61(6):567-74.

31. Handsaker JC, Brown SJ, Bowling FL, Maganaris CN, Boulton AJ, Reeves ND. Resistance exercise training increases lower limb speed of strength generation during stair ascent and descent in people with diabetic peripheral neuropathy. Diabet Med. 2016:33(1):97104.

32. Clemson L, Cumming RG, Kendig H, Swann M, Heard R, Taylor K. The effectiveness of a community-based program for reducing the incidence of falls in the elderly: a randomized trial. J Am Geriatr Soc. 2004:52(9):1487-94.

33. Iversen MM, Midthjell K, Tell GS, Moum T, Østbye T, Nortvedt MW, et al. The association between history of diabetic foot ulcer, perceived health and psychological distress: the Nord-Trøndelag Health Study. BMC Endocrine Disorders. 2009:9:7p-p.

34. Ismail K, Winkley K, Stahl D, Chalder T, Edmonds M. A cohort study of people with diabetes and their first foot ulcer: the role of depression on mortality. Diabetes care. 2007:30(6):1473-9. A report on high prevalence of clinical depression in diabetic foot ulcer patients and its association with increased mortality.

35. Winkley K, Sallis H, Kariyawasam D, Leelarathna LH, Chalder T, Edmonds ME, et al. Fiveyear follow-up of a cohort of people with their first diabetic foot ulcer: the persistent effect of depression on mortality. Diabetologia. 2012:55(2):303-10.

36. Williams LH, Rutter CM, Katon WJ, Reiber GE, Ciechanowski P, Heckbert SR, et al. Clinical research study: Depression and Incident Diabetic Foot Ulcers: A Prospective Cohort Study. The American Journal of Medicine. 2010:123:748-54. An epidemiologic investigation that linked major depression to a 2 -fold increased risk of incident diabetic foot ulcers.

37. Iversen MM, Tell GS, Espehaug B, Midthjell K, Graue M, Rokne B, et al. Is depression a risk factor for diabetic foot ulcers? 11-years follow-up of the Nord-Trondelag Health Study (HUNT). J Diabetes Complications. 2015:29(1):20-5. 
38. - Gonzalez JS, Vileikyte L, Ulbrecht JS, Rubin RR, Garrow AP, Delgado C, et al. Depression predicts first but not recurrent diabetic foot ulcers. Diabetologia. 2010:53(10):2241-8. A prospective study of well-defined neuropathy population while confirming that depression is a risk factor for incident first foot ulcers challenges foot self-care as a mechanism linking depression to foot ulceration.

39. Gonzalez JS, Peyrot M, McCarl LA, Collins EM, Serpa L, Mimiaga MJ, et al. Depression and diabetes treatment nonadherence: a meta-analysis. Diabetes Care. 2008:31(12):2398-403.

40. Brownlee $S$, Leventhal EA, Leventhal $H$. Regulation, self-regulation and regulation of the self in maintaining physical health. . In: Boekartz M, Pintrich PR, Zeidner M, editors. Handbook of Self-Regulation. San Deiego: Academic Press; 2000. p. 369-416.

41. - Vileikyte L, Gonzalez JS, Leventhal H, Peyrot MF, Rubin RR, Garrow A, et al. Patient Interpretation of Neuropathy (PIN) Questionnaire: an instrument for assessment of cognitive and emotional factors associated with foot self-care. Diabetes care. 2006:29(12):2617-24. Psychometric validation of the instument that captures characteristic misconceptions about neuropathy as the foot ulcer risk and associated emotions that shape preventive foot self-care.

42. Perrin BM, Swerissen H, Payne CB, Skinner TC. Cognitive representations of peripheral neuropathy and self-reported foot-care behaviour of people at high risk of diabetesrelated foot complications. Diabet Med. 2014:31(1):102-6.

43. French DP, Wade AN, Farmer AJ. Predicting self-care behaviours of patients with type 2 diabetes: the importance of beliefs about behaviour, not just beliefs about illness. J Psychosom Res. 2013:74(4):327-33.

44. Arts ML, de Haart M, Bus SA, Bakker JP, Hacking HG, Nollet F. Perceived usability and use of custom-made footwear in diabetic patients at high risk for foot ulceration. Journal of rehabilitation medicine. 2014:46(4):357-62.

45. Waaijman R, Keukenkamp R, de Haart M, Polomski WP, Nollet F, Bus SA. Adherence to wearing prescription custom-made footwear in patients with diabetes at high risk for plantar foot ulceration. Diabetes Care. 2013:36(6):1613-8.

46. - Crews RT, Schneider KL, Yalla SV, Reeves ND, Vileikyte L. Physiological and Psychological Challenges of Increasing Physical Activity and Exercise in Patients at Risk of Diabetic Foot Ulcers: A Critical Review. Diabetes Metab Res Rev. 2016. A comprehensive overview of research into physical activity in patients at high risk of foot ulceration.

47. Colberg SR, Sigal RJ, Fernhall B, Regensteiner JG, Blissmer BJ, Rubin RR, et al. Exercise and type 2 diabetes: the American College of Sports Medicine and the American Diabetes Association: joint position statement. Diabetes Care. 2010:33(12):e147-67.

48. Mendes R, Sousa N, Reis VM, Themudo-Barata JL. Prevention of exercise-related injuries and adverse events in patients with type 2 diabetes. Postgrad Med J. 2013:89(1058):715-21.

49. Katon WJ, Russo JE, Heckbert SR, Lin EH, Ciechanowski P, Ludman E, et al. The relationship between changes in depression symptoms and changes in health risk behaviors in patients with diabetes. International journal of geriatric psychiatry. 2010:25(5):466-75. 
50. Crews RT, Yalla SV, Fleischer AE, Wu SC. A growing troubling triad: diabetes, aging, and falls. J Aging Res. 2013:2013:342650.

51. Kluding PM, Pasnoor M, Singh R, Jernigan S, Farmer K, Rucker J, et al. The effect of exercise on neuropathic symptoms, nerve function, and cutaneous innervation in people with diabetic peripheral neuropathy. Journal of diabetes and its complications.

2012:26:424-9.

52. Yoo M, D'Silva U, Martin K, Sharma NK, Pasnoor M, LeMaster JW, et al. Pilot Study of Exercise Therapy on Painful Diabetic Peripheral Neuropathy. Pain Medicine (Malden, Mass). 2015.

53. - Glaser R, Kiecolt-Glaser JK. Stress-induced immune dysfunction: implications for health. Nat Rev Immunol. 2005:5(3):243-51. A superb overview of the effects and mechanisms by which psychological stress influences health outcomes.

54. - Monami M, Longo R, Desideri CM, Masotti G, Marchionni N, Mannucci E. The diabetic person beyond a foot ulcer: healing, recurrence, and depressive symptoms. J Am Podiatr Med Assoc. 2008:98(2):130-6. The first investigation linking depression to foot ulcer nonhealing and recurrence.

55. Vedhara K, Miles JN, Wetherell MA, Dawe K, Searle A, Tallon D, et al. Coping style and depression influence the healing of diabetic foot ulcers: observational and mechanistic evidence. Diabetologia. 2010:53(8):1590-8.

56. Gonzalez JS, Hardman MJ, Boulton AJ, Vileikyte L. Coping and depression in diabetic foot ulcer healing: causal influence, mechanistic evidence or none of the above? Diabetologia. 2011:54(1):205-6.

57. Razjouyan J, Grewal GS, Talal TK, Armstrong DG, Mills JL, Najafi B. Does Physiological Stress Slow Down Wound Healing in Patients With Diabetes? J Diabetes Sci Technol. 2017 (in press)

58. Lavery LA, Fleishli JG, Laughlin TJ, Vela SA, Lavery DC, Armstrong DG. Is postural instability exacerbated by off-loading devices in high risk diabetics with foot ulcers? Ostomy Wound Manage. 1998:44(1):26-32, 4.

59. van Deursen R. Footwear for the neuropathic patient: offloading and stability. Diabetes Metab Res Rev. 2008:24 Suppl 1:S96-S100.

60. Goodworth AD, Kunsman M, DePietro V, LaPenta G, Miles K, Murphy J. Characterization of How a Walking Boot Affects Balance. Journal of Prosthetics and Orthotics. 2014:26(1):6.

61. Bus SA, van Netten JJ. A shift in priority in diabetic foot care and research: $75 \%$ of foot ulcers are preventable. Diabetes Metab Res Rev. 2016:32 Suppl 1:195-200.

62. Crews RT, Sayeed F, Najafi B. Impact of strut height on offloading capacity of removable cast walkers. Clin Biomech (Bristol, Avon). 2012:27(7):725-30.

63. Keylock KT, Vieira VJ, Wallig MA, DiPietro LA, Schrementi M, Woods JA. Exercise accelerates cutaneous wound healing and decreases wound inflammation in aged mice. American journal of physiology Regulatory, integrative and comparative physiology. 2008:294(1):R179-84.

64. Emery CF, Kiecolt-Glaser JK, Glaser R, Malarkey WB, Frid DJ. Exercise accelerates wound healing among healthy older adults: a preliminary investigation. J Gerontol A Biol Sci Med Sci. 2005:60(11):1432-6. 
65. Pence BD, Woods JA. Exercise, Obesity, and Cutaneous Wound Healing: Evidence from Rodent and Human Studies. Adv Wound Care (New Rochelle). 2014:3(1):71-9.

66. Pence BD, Dipietro LA, Woods JA. Exercise speeds cutaneous wound healing in high-fat diet-induced obese mice. Med Sci Sports Exerc. 2012:44(10):1846-54.

67. Gouin JP, Kiecolt-Glaser JK. The impact of psychological stress on wound healing: methods and mechanisms. Immunol Allergy Clin North Am. 2011:31(1):81-93.

68. Gleeson M, Bishop NC, Stensel DJ, Lindley MR, Mastana SS, Nimmo MA. The antiinflammatory effects of exercise: mechanisms and implications for the prevention and treatment of disease. Nat Rev Immunol. 2011:11(9):607-15.

69. Vanross ER, Johnson S, Abbott CA. Effects of early mobilization on unhealed dysvascular transtibial amputation stumps: a clinical trial. Arch Phys Med Rehabil. 2009:90(4):610-7.

70. - Najafi B, Grewal GS, Bharara M, Menzies R, Talal TK, Armstrong DG. Can't Stand the Pressure: The Association Between Unprotected Standing, Walking, and Wound Healing in People With Diabetes. J Diabetes Sci Technol. 2016. The first investigation of the effects of physical activity on foot ulcer healing in diabetes.

71. Vileikyte L, Shen BJ, Brouwn S, Boulton AJM, Kirsner RS, Reeves ND, et al. Depression, Physical Activity, and Diabetic Foot Ulcer Healing. American Diabetes Association's 77th Scientific Sessions; June 9-13; San Deigo, California, USA 2017. 

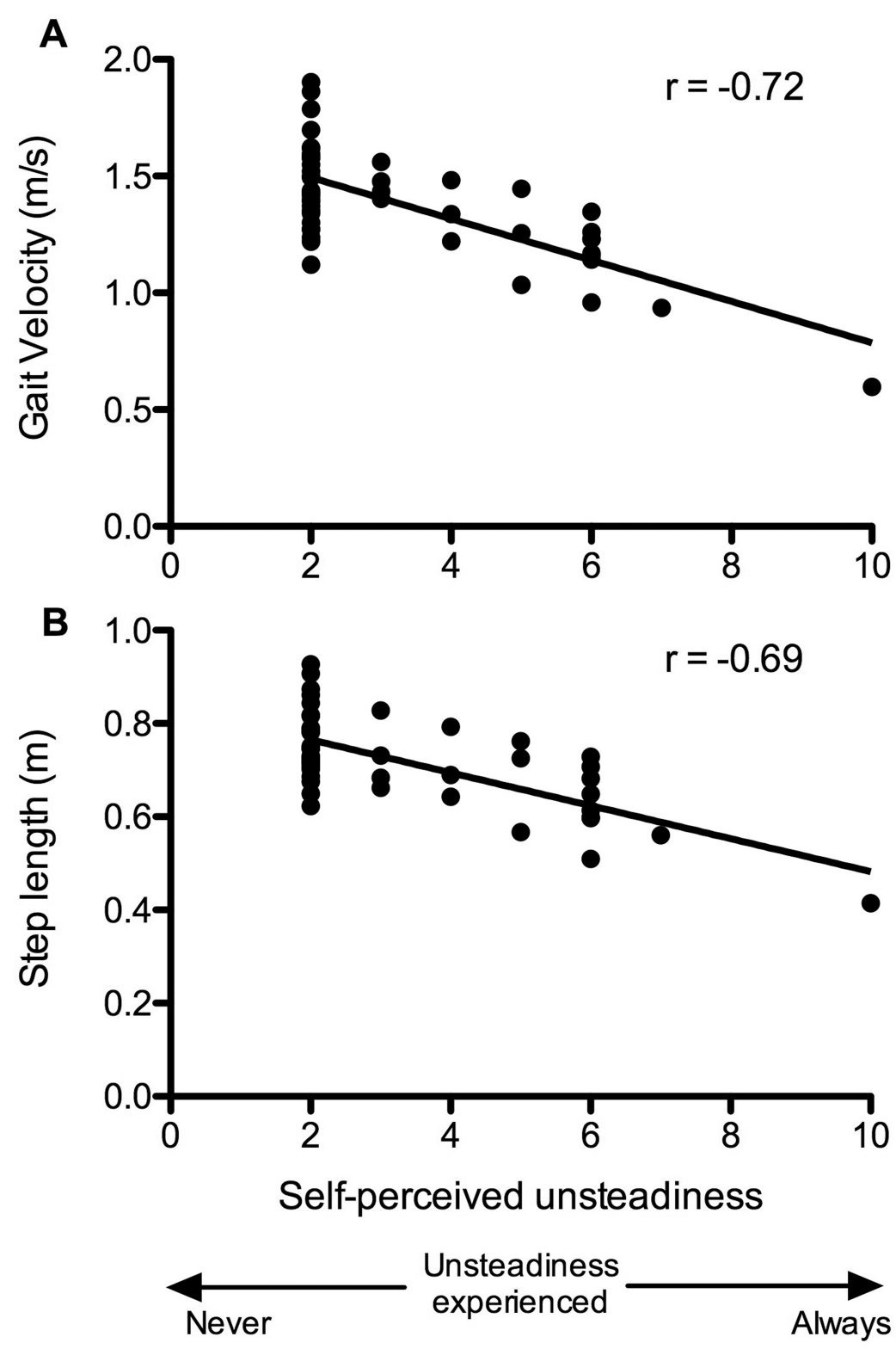

Figure 1. Data from individual participants showing gait velocity $(\mathbf{A})$ and step length (B) from gait laboratory measurements, plotted as a function of self-perceived unsteadiness ( $n=49$ : 15 participants with moderate-severe diabetic peripheral neuropathy; 15 participants with diabetes but no peripheral neuropathy; 19 control participants without diabetes or peripheral neuropathy). A linear regression line has been fitted through the data points and the Pearson's correlation coefficient values indicated. Perception of unsteadiness scores have been combined for walking and standing. Original unpublished data from Reeves et al., $(\cdot 27)$. 
Table 1: Recent studies of exercise interventions for individuals with diabetic peripheral neuropathy.

\begin{tabular}{|c|c|c|c|c|c|c|c|c|c|c|c|}
\hline \multirow[b]{2}{*}{ Authors } & \multirow[b]{2}{*}{ Year } & \multirow[b]{2}{*}{ Study type } & \multirow[b]{2}{*}{ Patients } & \multicolumn{7}{|c|}{ Exercise } & \multirow[b]{2}{*}{ Results } \\
\hline & & & & Equipment & Type & Frequency & Intensity & Duration & Period & $\begin{array}{c}\text { Supervised } \\
\text { by }\end{array}$ & \\
\hline $\begin{array}{c}\text { Kanchana } \\
\& \text { Pensri }\end{array}$ & 2017 & RCT & $\begin{array}{l}21 \text { DPN } \\
\text { diabetes } \\
\text { type not } \\
\text { reported }\end{array}$ & $\begin{array}{c}\text { Mini } \\
\text { trampoline }\end{array}$ & $\begin{array}{l}\text { Aerobic } \\
\text { weight } \\
\text { bearing } \\
\text { activity }\end{array}$ & $\begin{array}{l}5 \text { times per } \\
\text { week }\end{array}$ & $\begin{array}{l}\text { Aerobic- moderate } \\
\text { intensity that } \\
\text { increased over time }\end{array}$ & $\begin{array}{c}20-25 \\
\text { minutes }\end{array}$ & $\begin{array}{c}8 \\
\text { weeks }\end{array}$ & $\begin{array}{l}\text { Home based } \\
\text { exercise } \\
\text { program }\end{array}$ & $\begin{array}{c}\text { Increased } \\
\text { mobility of the } \\
1^{\text {st }} \text { MTPJ and } \\
\text { improved } \\
\text { somatosensory } \\
\text { perception }\end{array}$ \\
\hline $\begin{array}{l}\text { Handsaker } \\
\text { et al. }\end{array}$ & 2016 & $\mathrm{RCT}$ & $\begin{array}{l}13 \mathrm{DM} / \\
9 \mathrm{DPN} / \\
21 \mathrm{Con} \\
\mathrm{T} 1 \& \mathrm{~T} 2\end{array}$ & $\begin{array}{l}\text { Resistance } \\
\text { machines }\end{array}$ & $\begin{array}{l}\text { Lower } \\
\text { extremity } \\
\text { resistance } \\
\text { training }\end{array}$ & $\begin{array}{l}1 \text { time per } \\
\text { week }\end{array}$ & Heavy resistance & $60 \mathrm{~min}$ & $\begin{array}{c}16 \\
\text { weeks }\end{array}$ & Investigator & $\begin{array}{l}\text { Improved speed } \\
\text { of strength } \\
\text { generation during } \\
\text { ascending/ } \\
\text { descending stairs }\end{array}$ \\
\hline Dixit et al. & $\begin{array}{l}2014 \\
\& \\
2016\end{array}$ & RCT & $\begin{array}{c}87 \mathrm{DPN} \\
\mathrm{T} 2\end{array}$ & Treadmill & aerobic & $\begin{array}{c}150-360 \\
\mathrm{~min} / \text { week }\end{array}$ & 40 to $60 \%$ of HRR & variable & $\begin{array}{c}8 \\
\text { weeks }\end{array}$ & Investigator & $\begin{array}{c}\text { progression of } \\
\text { DPN was } \\
\text { reduced and } \\
\text { QOL improved } \\
\text { in the } \\
\text { intervention } \\
\text { group without } \\
\text { increased adverse } \\
\text { events }\end{array}$ \\
\hline $\begin{array}{l}\text { Singleton } \\
\text { et al. }\end{array}$ & 2015 & $\begin{array}{l}\text { Prospective } \\
\text { Interventional }\end{array}$ & $\begin{array}{c}35 \mathrm{DM} / \\
32 \mathrm{DPN} \\
\mathrm{T} 2\end{array}$ & Treadmill & $\begin{array}{l}\text { aerobic/ } \\
\text { resistance }\end{array}$ & $150 \mathrm{~min} /$ week & $\begin{array}{c}\text { moderate } 11 \text { to } 14 \\
\text { Borg Perceived } \\
\text { Exertion scale }\end{array}$ & $\begin{array}{c}30 \text { to } 90 \\
\min \end{array}$ & $\begin{array}{c}18 \\
\text { weeks }\end{array}$ & $\begin{array}{c}\text { PhD trained } \\
\text { Physical } \\
\text { Therapist }\end{array}$ & $\begin{array}{l}\text { improved } \\
\text { cutaneous } \\
\text { regeneration, } \\
\text { increased } \\
\text { intraepidermal } \\
\text { nerve fiber } \\
\text { density }\end{array}$ \\
\hline
\end{tabular}




\begin{tabular}{|c|c|c|c|c|c|c|c|c|c|c|c|}
\hline $\begin{array}{l}\text { Kluding et } \\
\text { al. }\end{array}$ & 2015 & $\begin{array}{c}\text { Prospective } \\
\text { Interventional }\end{array}$ & $\begin{array}{c}18 \mathrm{DPN} \\
\mathrm{T} 2\end{array}$ & $\begin{array}{l}\text { cycle } \\
\text { ergometer, } \\
\text { treadmills, } \\
\text { recumbent } \\
\text { steppers, } \\
\text { elliptical } \\
\text { trainers }\end{array}$ & aerobic & $\begin{array}{l}3 \text { times per } \\
\text { week }\end{array}$ & $\begin{array}{c}50 \text { to } 70 \% \text { of } \mathrm{VO} 2 \\
\text { reserve }\end{array}$ & $\begin{array}{l}30 \text { to } 50 \\
\min \end{array}$ & $\begin{array}{c}16 \\
\text { weeks }\end{array}$ & $\begin{array}{c}\text { Licensed } \\
\text { health care } \\
\text { professionals }\end{array}$ & $\begin{array}{c}\text { Supervised } \\
\text { aerobic exercise } \\
\text { in DPN } \\
\text { population is } \\
\text { feasible }\end{array}$ \\
\hline $\begin{array}{l}\text { Morrison } \\
\text { et al. }\end{array}$ & 2014 & $\begin{array}{l}\text { Prospective } \\
\text { Interventional }\end{array}$ & $\begin{array}{c}21 \mathrm{DM} / \\
16 \mathrm{DPN} \\
\mathrm{T} 2\end{array}$ & $\begin{array}{c}\text { cycle } \\
\text { ergometers } \\
\text { treadmills, } \\
\text { elliptical } \\
\text { strider }\end{array}$ & aerobic & $\begin{array}{l}3 \text { times per } \\
\text { week }\end{array}$ & $\begin{array}{c}\text { Moderate@50\% } \\
\text { HRR; Vigorous } \\
@ 75 \% \text { HRR }\end{array}$ & $\begin{array}{l}\text { Moderate } \\
-45 \mathrm{~min} \\
\text { Vigorous } \\
-30 \mathrm{~min}\end{array}$ & $\begin{array}{c}12 \\
\text { weeks }\end{array}$ & $\begin{array}{l}\text { only for peak } \\
\text { testing on } \\
\text { cycle } \\
\text { ergometer }\end{array}$ & $\begin{array}{l}\text { gait velocity, step } \\
\text { length increased } \\
\text { significantly after } \\
\text { intervention }\end{array}$ \\
\hline $\begin{array}{l}\text { Mueller et } \\
\quad \text { al. }\end{array}$ & 2013 & $\mathrm{RCT}$ & $\begin{array}{c}29 \mathrm{DPN} \\
\mathrm{T} 2\end{array}$ & $\begin{array}{l}\text { Treadmill, } \\
\text { resistance } \\
\text { bands and } \\
\text { stationary } \\
\text { bicycle }\end{array}$ & aerobic & $\begin{array}{l}3 \text { times per } \\
\text { week }\end{array}$ & $\begin{array}{c}60 \text { to } 70 \% \text { age } \\
\text { predicted max HR }\end{array}$ & variable & $\begin{array}{c}12 \\
\text { weeks }\end{array}$ & $\begin{array}{l}\text { Licensed } \\
\text { Physical } \\
\text { Therapist }\end{array}$ & $\begin{array}{c}\text { Weight bearing } \\
\text { group improved } \\
\text { step count and } 6 \\
\text { min walk } \\
\text { distance } \\
\text { compared to non- } \\
\text { weight bearing. } \\
13 \text { lesions and } 4 \\
\text { ulcers were } \\
\text { observed, } 3 \text { in } \\
\text { non-weight } \\
\text { bearing group. }\end{array}$ \\
\hline
\end{tabular}

Note: Con = non-diabetic control participants; $D M=$ non-neuropathic participants with diabetes mellitus; $D P N=$ participants with diabetic peripheral neuropathy; HR= heart rate; HRR= heart rate reserve; MTPJ = metatarsalphalangeal joint; $\mathrm{QOL}=$ quality of life; $\mathrm{RCT}=$ randomized controlled trial; $\mathrm{T} 1=$ participants with type 1 diabetes mellitus; T2 = participants with type 2 diabetes mellitus 
